\title{
Case-Initiated COVID-19 Contact Tracing Using Anonymous Notifications
}

\author{
Weibin Cheng ${ }^{1}$, MSc; Chun $\mathrm{Hao}^{2,3}, \mathrm{PhD}$ \\ ${ }^{1}$ Institute for Healthcare Artificial Intelligence Application, Guangdong Second Provincial General Hospital, Guangzhou, China \\ ${ }^{2}$ Department of Medical Statistics and Sun Yat-sen Global Health Institute, School of Public Health \& Institute of State Governance, Sun Yat-sen \\ University, Guangzhou, China \\ ${ }^{3}$ Health Information Research Center and Guangdong Key Laboratory of Medicine, School of Public Health, Sun Yat-sen University, Guangzhou, \\ China
}

\section{Corresponding Author:}

Weibin Cheng, MSc

Institute for Healthcare Artificial Intelligence Application

Guangdong Second Provincial General Hospital

466 Xingangzhong Road

Guangzhou, 510317

China

Phone: 862089168139

Email: chwb817@gmail.com

\section{Abstract}

We discuss the concept of a participatory digital contact notification approach to assist tracing of contacts who are exposed to confirmed cases of coronavirus disease (COVID-19); the approach is simple and affordable for countries with limited access to health care resources and advanced technology. The proposed tool serves as a supplemental contract tracing approach to counteract the shortage of health care staff while providing privacy protection for both cases and contacts. This tool can be deployed on the internet or as a plugin for a smartphone app. Confirmed cases with COVID-19 can use this tool to provide contact information (either email addresses or mobile phone numbers) of close contacts. The system will then automatically send a message to the contacts informing them of their contact status, what this status means, the actions that should follow (eg, self-quarantine, respiratory hygiene/cough etiquette), and advice for receiving early care if they develop symptoms. The name of the sender of the notification message by email or mobile phone can be anonymous or not. The message received by the contact contains no disease information but contains a security code for the contact to log on the platform to retrieve the information.

(JMIR Mhealth Uhealth 2020;8(6):e20369) doi: $\underline{10.2196 / 20369}$

\section{KEYWORDS}

COVID-19; surveillance; contact tracing; digital contact tracing; notification; anonymous; labor-saving; stigma; privacy protection

\section{Introduction}

Emerging evidence from the response to coronavirus disease (COVID-19) in China [1], Singapore [2,3], and South Korea [4] has indicated that efficient contact tracing reduces the delay between infection and isolation and accordingly prevents further transmission of the virus [5,6]. Contact tracing, which includes contact identification, listing, and follow-up, is a crucial aspect of epidemic control and is usually driven by health specialists. Contact tracing is a tedious task that requires enormous staff resources, and it is not possible to fully implement contact tracing in regions with widespread transmission. Alternatively, some parts of this task can be substituted and even augmented by technology.
Luca Ferretti and colleagues [1] modelled the potential effect of a digital contact tracing approach that involved training an artificial intelligence algorithm to analyze COVID-19 cases and GPS-based population colocalization information. However, the application of this powerful method may be hindered by advanced technical requirements and violation of privacy regulations. Yasaka and colleagues [7] developed a proof-of-concept smartphone app that allows users to create "checkpoints" for contact tracing and also modelled the effect of such an app under various adoption scenarios. This app respects user privacy by not collecting location information or other personal data. However, this approach relies on high levels of vigilance and willingness to participate among a majority of the population. Another concept of "privacy by design" COVID-19 contact tracing via Bluetooth is being rolled out in 
Europe [8] which relies on Bluetooth data exchange between two mobile phones to detect whether two people have come into sufficient physical proximity to risk infection, and notifying those who have been in contact with an infected individual who stays anonymous. This type of app has the same constraint of requiring user cooperation to have any chance of success, and it may be more useful in developed countries where smartphones are widely used.

Health care staff resources have been scarce worldwide during the COVID-19 pandemic, especially in developing countries, where technological resources may also be inadequate. We discuss a concept of a contact notification tool to assist tracing of contacts who are exposed to confirmed cases of COVID-19; this tool is simple and affordable for countries with limited access to health care staff and advanced technology.

\section{Concept of the Tool}

The core functionality of our concept is to provide a usable, labor-saving tool for contact tracing by confirmed cases themselves (Table 1). This tool serves as a supplemental contract tracing approach to counteract the shortage of health care staff while providing privacy protection for both cases and contacts. This tool can be deployed on the internet or as a plugin for a smartphone app. Confirmed cases with COVID-19 can use this tool to provide contact information (either email addresses or mobile phone numbers) of close contacts; then, the system will automatically send a message to the contacts informing them of their contact status, what this status means, the actions that should follow (eg, self-quarantine, respiratory hygiene/cough etiquette), and advice for receiving early care if they develop symptoms. The name of the sender of the notification message by email or mobile phone can be anonymous or not. The message received by the contact contains no disease information but contains a security code for the contact to log on the platform to retrieve the information. This approach can prevent reading of the message by people other than the intended recipient. The personal identification data of both the confirmed case and their close contacts will not be recorded during the process. Information provided by confirmed cases will also be encrypted.

Table 1. Concept framework for the development of a tool for COVID-19 contact tracing.

\begin{tabular}{|c|c|}
\hline Concept & Descriptions and considerations \\
\hline \multirow[t]{2}{*}{ Products } & Smartphone app \\
\hline & Web-based platform \\
\hline \multirow[t]{2}{*}{ Operating systems } & Windows and Apple \\
\hline & App compatible with the latest smartphone operating systems \\
\hline \multirow[t]{5}{*}{ Target users } & Suspected and confirmed cases with COVID-19 \\
\hline & People who receive messages from the platform \\
\hline & People who are concerned about COVID-19 infection \\
\hline & People who need guidance regarding the control and prevention of COVID-19 \\
\hline & Policy makers and public health specialists \\
\hline \multirow[t]{3}{*}{ Functionality } & Contact notification (eg, email, SMS text messages, autochatbot); can be anonymous or not \\
\hline & Shared exposure query database \\
\hline & COVID-19 information hub (optional but strongly recommended) \\
\hline \multirow[t]{3}{*}{ Application scenarios } & Cases when in-person investigation cannot be implemented \\
\hline & Regions and countries where manual contact tracing is not in place \\
\hline & $\begin{array}{l}\text { Supplement to manual contact tracing, especially in regions of widespread transmission where people with no } \\
\text { or mild symptoms are self-quarantined at home }\end{array}$ \\
\hline \multirow[t]{6}{*}{ Navigation and use of the tool } & Clear definition of close contacts of COVID-19 \\
\hline & Guide for generation of close contacts \\
\hline & Official email account or telephone number \\
\hline & Template notification messages \\
\hline & Rights and responsibilities \\
\hline & Online consultation \\
\hline \multirow[t]{4}{*}{ Other considerations } & Paramount protection of personal privacy \\
\hline & $\begin{array}{l}\text { Strict adherence to general data protection regulations, careful oversight of data, and effective protections around } \\
\text { the use of data }\end{array}$ \\
\hline & Guaranteed equity of access to testing and treatment \\
\hline & Careful design and monitoring to prevent malicious use \\
\hline
\end{tabular}


Another key functionality is a shared exposure query database for people whose close contacts cannot be reached by messaging. This design is a crowdsourced database that allows patients to input their trajectory information, including public transportation used and times and locations of the patient's movement prior to and after onset of symptoms. Trajectory information can either be provided by the confirmed patient or obtained during confirmation and uploaded by an epidemiologist. This trajectory information can be visualized on a map, which may be useful for the public to determine their possible exposure to COVID-19. The tool should be simple and easy to access so that it can be used in areas with limited resources. For example, people can visit the website and search by date and route for possible close contact with a patient with COVID-19. This tool can also serve as a hub to access instructions and information about COVID-19 and health services.

\section{Benefits of the Tool}

We envisage that this tool will be useful for people who are concerned about personal privacy and stigmatization related to COVID-19. Persons of Asian descent have faced stigma and discrimination in many places [9]. A person can also be subjected to stigma after they have been released from COVID-19 quarantine even though they are not considered to be at risk of spreading the virus to others. Several digital contact tracing approaches have been explored worldwide [10]. Despite the potential of digital contact tracing, its potential impact is limited because it may conflict with patient data privacy regulations. Our approach is different from other digital contact tracing methods in two ways. One is that it can be function as a website that does not need to be installed on the user's smartphone. This will substantially lower the threshold for users to access the tool. The other is that no data processing, recording, or analysis occurs on the central server, which reduces concerns regarding personal privacy.

Meanwhile, this approach can be used as a supplement contact tracing tool in regions of widespread transmission where many undiagnosed mild cases are self-isolating at home, such as the
United States and United Kingdom. This tool can help save health care resources, freeing staff to provide more urgent testing and clinical care for patients with COVID-19. Although mild cases who self-isolate at home may not associated with the spread of COVID-19, promptly informing contacts of possible risks to take proper precaution measures seems to be necessary and reasonable during a disease outbreak.

\section{Considerations for Successful Use}

Several considerations should be taken into account to guarantee the successful use of this tool. First, the main purpose of this tool is to provide a supplementary approach for patients with COVID-19 to inform their friends, colleagues, and neighbors about possible contact while maintaining their privacy. Second, an accessible COVID-19 testing and care network is needed to guarantee equity of access to testing and treatment to meet the surging demand and relieve the anxiety of people who have received notifications and are anxious about possible infection. Third, privacy protection for both the sender and the recipient are equally important. The General Data Protection Regulation must be strictly followed, and careful oversight and effective protection of the use of data must be ensured. Last, we need to be alert to possible malicious use of this tool. People who do not have COVID-19 may use the system to send messages to others for evil purposes.

\section{Conclusion}

The successful application of this tool relies heavily on public social responsibility and credibility, and it remains to be seen if the public would adopt such a tool and what mechanisms are required to prevent misuse. This is a simple tool that does not require complicated computer techniques despite strict user privacy protection design with respect to countries and regions. Additionally, this tool can help avoid coercive surveillance, facilitate the allocation of health resources, and prioritize clinical service for patients with COVID-19. Information obtained from the platform can also increase our understanding of the epidemiology of COVID-19.

\section{Conflicts of Interest}

None declared.

\section{References}

1. Ferretti L, Wymant C, Kendall M, Zhao L, Nurtay A, Abeler-Dörner L, et al. Quantifying SARS-CoV-2 transmission suggests epidemic control with digital contact tracing. Science 2020 May 08;368(6491) [FREE Full text] [doi: 10.1126/science.abb6936] [Medline: $\underline{32234805}$ ]

2. Koo JR, Cook AR, Park M, Sun Y, Sun H, Lim JT, et al. Interventions to mitigate early spread of SARS-CoV-2 in Singapore: a modelling study. Lancet Infect Dis 2020 Jun;20(6):678-688 [FREE Full text] [doi: 10.1016/s1473-3099(20)30162-6] [Medline: 32213332$]$

3. Pung R, Chiew C, Young B, Chin S, Chen MI, Clapham HE, et al. Investigation of three clusters of COVID-19 in Singapore: implications for surveillance and response measures. Lancet 2020 Mar;395(10229):1039-1046 [FREE Full text] [doi: 10.1016/S0140-6736(20)30528-6] [Medline: 32192580]

4. COVID-19 National Emergency Response Center, EpidemiologyCase Management Team, Korea Centers for Disease ControlPrevention. Coronavirus Disease-19: Summary of 2,370 Contact Investigations of the First 30 Cases in the Republic of Korea. Osong Public Health Res Perspect 2020 Apr;11(2):81-84 [FREE Full text] [doi: 10.24171/j.phrp.2020.11.2.04] [Medline: 32257773] 
5. McMichael TM, Currie DW, Clark S, Pogosjans S, Kay M, Schwartz NG, et al. Epidemiology of Covid-19 in a Long-Term Care Facility in King County, Washington. N Engl J Med 2020 May 21;382(21):2005-2011 [FREE Full text] [doi: 10.1056/nejmoa2005412] [Medline: $\underline{32220208]}$

6. Hellewell J, Abbott S, Gimma A, Bosse NI, Jarvis CI, Russell TW, et al. Feasibility of controlling COVID-19 outbreaks by isolation of cases and contacts. Lancet Glob Health 2020 Apr;8(4):e488-e496 [FREE Full text] [doi: 10.1016/s2214-109x(20)30074-7] [Medline: 32119825]

7. Yasaka TM, Lehrich BM, Sahyouni R. Peer-to-Peer Contact Tracing: Development of a Privacy-Preserving Smartphone App. JMIR Mhealth Uhealth 2020 Apr 07;8(4):e18936 [FREE Full text] [doi: 10.2196/18936] [Medline: $\underline{32240973]}$

8. Abeler J, Bäcker M, Buermeyer U, Zillessen H. COVID-19 Contact Tracing and Data Protection Can Go Together. JMIR Mhealth Uhealth 2020 Apr 20;8(4):e19359 [FREE Full text] [doi: 10.2196/19359] [Medline: 32294052]

9. Shimizu K. 2019-nCoV, fake news, and racism. Lancet 2020 Feb;395(10225):685-686 [FREE Full text] [doi: 10.1016/s0140-6736(20)30357-3] [Medline: 32059801]

10. Ekong I, Chukwu E, Chukwu M. COVID-19 Mobile Positioning Data Contact Tracing and Patient Privacy Regulations: Exploratory Search of Global Response Strategies and the Use of Digital Tools in Nigeria. JMIR Mhealth Uhealth 2020 Apr 27;8(4):e19139 [FREE Full text] [doi: 10.2196/19139] [Medline: 32310817]

\section{Abbreviations \\ COVID-19: coronavirus disease}

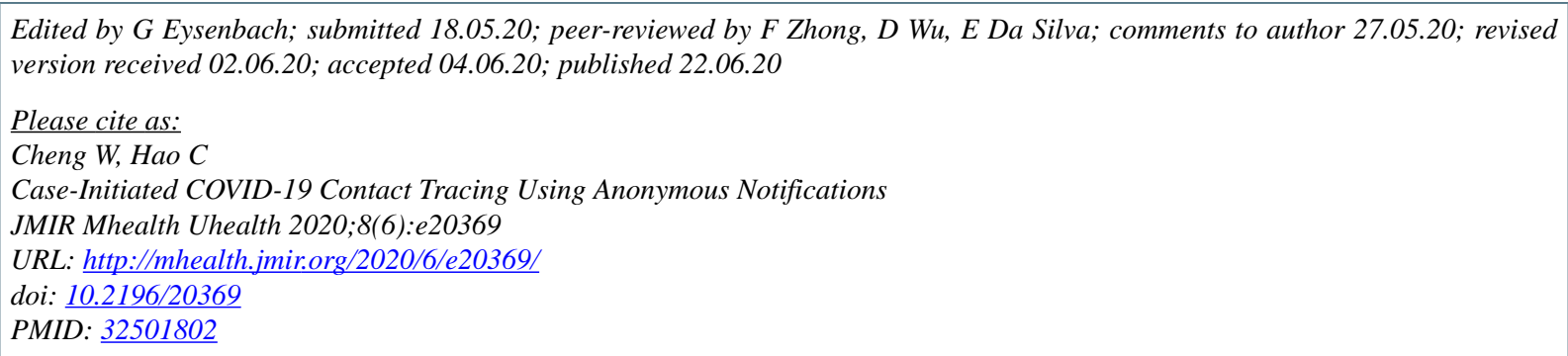

(C) Weibin Cheng, Chun Hao. Originally published in JMIR mHealth and uHealth (http://mhealth.jmir.org), 22.06.2020. This is an open-access article distributed under the terms of the Creative Commons Attribution License (https://creativecommons.org/licenses/by/4.0/), which permits unrestricted use, distribution, and reproduction in any medium, provided the original work, first published in JMIR mHealth and uHealth, is properly cited. The complete bibliographic information, a link to the original publication on http://mhealth.jmir.org/, as well as this copyright and license information must be included. 